\title{
Determination of measles, rubella, mumps and chickenpox seropositivity of district public hospital healthcare workers
}

\author{
DDilek Yekenkurul \\ Department of Infectious Diseases and Clinical Microbiology, Düzce University Faculty of Medicine, Düzce, Turkey
}

Cite this article as: Yekenkurul D. Determination of measles, rubella, mumps and chickenpox seropositivity of district public hospital healthcare workers. Anatolian Curr Med J 2021; 3(2); 109-114.

\begin{abstract}
Aim: Measles, rubella, mumps and chickenpox are the childhood diseases retain their importance in our country as well as all over the world. Healthcare workers have high probability of transmission due to their occupational risk; however by taking necessary protective measures, the risk can be reduced. Determining the seropositivity rates of healthcare workers; it was aimed to compare vaccination rates before and after screening.

Material and Method: The personnel cards of 160 healthcare workers who worked in Akçakoca State Hospital, from January 2018- December 2018 were retrospectively scanned. Information of 100 personnel has been reached. Demographic characteristics such as age and gender; infection or vaccination history; measles, rubella, mumps and chickenpox IgG results; old vaccination information and last vaccination status were recorded.

Results: Total of 100 staffs, 19 (19\%) men and 81 (81\%) women, were included in the study. 89 staffs (89\%) were found to be immune to measles. After the scanning, 11 of the personnels who were not vaccinated or had incomplete vaccines saw that the measles IgG result was negative and eight of them agreed to be vaccinated. The seropositivity rate of rubella was $93 \%$. Five of the seven personnels with rubella IgG negative, agreed to be vaccinated. The lowest seropositivity rate was in mumps (79\%). 14 of the 21 people with mumps IgG negative were vaccinated. The highest seropositivity rate was in chickenpox ( $96 \%)$. Three of the four people with chickenpox IgG negative were vaccinated.

Conclusion: While the rate of vaccination for measles, rubella, mumps and chickenpox before screening is low (12\%); our post-screening rate has increased (34\%). For this reason, we think that healthcare workers should be screened for measles, rubella, mumps and chickenpox, and healthcare workers who are seronegative should be encouraged to vaccinate.
\end{abstract}

Keywords: Healthcare workers, measles, rubella, mumps, chicken pox

\section{INTRODUCTION}

Measles, rubella, mumps and chickenpox are the childhood diseases retain their importance in our country as well as all over the world. Undergoing these infections, which are highly contagious and generally symptomatic, in adulthood increases the morbidity and mortality rate (1). Healthcare workers (HCWs) are more likely to be exposed to infected materials such as blood, secretion, body fluid; therefore, they are people with an increased risk of infection compared to the community. Infections transmitted to HCWs put not only themselves, but also their families, other hospital staff and patients at risk. Therefore, vaccination of HCWs is a condition affecting public health (2).
Centers for disease control and prevention (CDC), according to current vaccine recommendations to healthcare professionals who are born in 1957 and later, with without serological evidence that has had the disease in; proposes two doses of measles and mumps, one or two doses of MMR vaccine for rubella, and two doses of chickenpox vaccine (3). Vaccination against infections such as measles, rubella and chickenpox reduces the incidence of the disease and significantly prevents health-related outbreaks (4). In our country, vaccines are recommended to against such infectious diseases and vaccines are provided free of charge; however, it is not mandatory. Vaccination of HCWs is also important in terms of health services not to be disrupted (5). 
Healthcare workers have a high probability of transmission due to their occupational risk; however, by taking necessary protective measures such as MMR and chickenpox vaccines, the risk can be reduced. Determining the seropositivity rates of HCWs; in addition, it was aimed to compare vaccination rates before and after screening test.

\section{MATERIAL AND METHOD}

After the approval of the hospital chief physician and the ethics committee approval was obtained from Düzce University Clinical Research Ethics Committee (permission granted: 07.01.2019, decision no: 244).The personnel cards of approximately $160 \mathrm{HCWs}$ who worked in Akçakoca State Hospital, a secondary center hospital, from January 2018- December 2018 were retrospectively scanned. Health workers who had screening for measles, rubella, mumps and chickenpox were identified. Information and test results of 100 staff who had scanned were reached through personal health cards and hospital database. Those who have incomplete information and results from other staff or those who have not agreed to take the blood test are not included in the study; while working in our hospital between the same dates, staff who left our hospital for any reason were included. In the light of the information stated in the health cards, age, gender, occupation, professional year, unit of employment, educational status, history of infection or vaccination for MMR and chickenpox, MMR and chickenpox IgG result, recommended vaccine information and vaccination were recorded.

In our hospital, periodic healthcare worker surveillance is carried out every year and measles, rubella, mumps and chickenpox IgG tests are performed on every new health worker. Some tests as measles, rubella, mumps and chickenpox IgG are done in the form of external laboratory service. In the results that obtained, measles IgG value is positive if $>11$ NTU (Nephelometric Turbidity Unit), negative if $<9 \mathrm{NTU}$, and borderline if it is between 9-11 NTU; rubella $\mathrm{IgG}$ value is positive if $>10 \mathrm{IU} / \mathrm{mL}$, negative if $<10 \mathrm{IU} / \mathrm{mL}$; mumps IgG value is positive if $>11$ NTU, negative if $<9 \mathrm{NTU}$, and borderline if value between 9-11 NTU; varicella IgG value was positive if $>11 \mathrm{NTU}$, negative if $<9$ NTU, and borderline if value between 9-11 NTU. In the results of staff, there was no need to control the values at the border in terms of cost and all of them were offered vaccination; therefore, those who are at the limit in the number and rate notifications are considered negative. Staff, those results were negative or borderline, who accepted the vaccine were vaccinated free of charge by the Ministry of Health in our hospital. No postvaccination control IgG test was required. Staff who had the recommended vaccine (two doses one month apart) after the test were considered seropositive.

\section{RESULTS}

A total of 100 staff, $19(19 \%)$ men and 81 (81\%) women, were included in the study. The age range of employees was between 21 and 58, and the average age was 34.92 \pm 8.23 years. Considering the professional year, eight staff have not yet completed one year, and the longest employee has been working for 34 years; the average professional year of the employees was found to be $8.85 \pm 8.48$ years. Demographic characteristics, occupation, professional year, unit of employment, educational status, numbers and percentages of the personnel are given in Table 1.

\begin{tabular}{|c|c|}
\hline \multicolumn{2}{|l|}{ Characteristics } \\
\hline \multicolumn{2}{|l|}{ Gender n (\%) } \\
\hline Male & $19(19 \%)$ \\
\hline Female & $81(81 \%)$ \\
\hline Average age & $34.92 \pm 8.23$ years \\
\hline The average of professional year & $8.85 \pm 8.48$ years \\
\hline \multicolumn{2}{|l|}{ Occupation n (\%) } \\
\hline Doctor & $21(21 \%)$ \\
\hline Nurse and midwife & $46(46 \%)$ \\
\hline Technician & $10(10 \%)$ \\
\hline Cleaning staff & $4(4 \%)$ \\
\hline Others1 & $19(19 \%)$ \\
\hline \multicolumn{2}{|l|}{ Unit of employment $\mathbf{n}(\%)$} \\
\hline Polyclinic & $24(24 \%)$ \\
\hline Emergency & $18(18 \%)$ \\
\hline Operating room & $17(17 \%)$ \\
\hline Service & $17(17 \%)$ \\
\hline Administration & $9(9 \%)$ \\
\hline Others2 & $15(15 \%)$ \\
\hline \multicolumn{2}{|l|}{ Education status n (\%) } \\
\hline Primary school & $5(5 \%)$ \\
\hline High school & $12(12 \%)$ \\
\hline Associate degree & $35(35 \%)$ \\
\hline License & $48(48 \%)$ \\
\hline
\end{tabular}

In total, 89 staffs $(89 \%)$ were found to be immune to measles. The average age of the 11 negative staff is $31.72 \pm 7.15$ years; those who were positive were $35.31 \pm 8.31$ years. Seven negative staffs were under 35 years old, four staffs were over 35 years old (39, 40, 40, 42 years old) and none were born before 1957. In terms of profession, five of the 11 staff were midwives or nurses, one was a doctor, one was a radiology technician, one was a cleaning staff, two were data entry staff, and the risk of transmission was quite high. Since there was no single measles vaccine, those who did not have any contraindications were offered two doses of MMR vaccine at one-month intervals. One of the staff previously stated that they had a MMR vaccine, but the result was at the border (9.9 NTU). This personnel had been vaccinated by us, but the vaccination information of other personnels was anamnestic data. According to the information on the personnel health cards, 10 of the 11 staff were in the group who did not know whether they 
had measles before or had no at all; however only one had been vaccinated; his level of protection was probably insufficient as he had vaccination once. However, eight of the 11 staff $(73 \%)$, who saw that they were negative after the test, agreed to be vaccinated and received two doses of MMR vaccine (Table 2). No post-vaccination control IgG test was required and was considered seropositive. The other three people did not agree to be vaccinated for different reasons.

The overall seropositivity rate of rubella was 93\% (Table 3 ). The mean age of rubella IgG values was calculated as $38.28 \pm 7.38$ years and $34.59 \pm 8.23$ years for positive ones. Only two of the seven were under 35 (28.33) and the other five were over 35 (38.40.42.43.51). The two did not agree to be vaccinated; Since five staff have MMR vaccine, we have received two doses of MMR vaccine at one month intervals. Of the seven negative people, one was a doctor, one was a civil servant and the other five were nurses.

Mumps IgG positivity rate was lowest with 79\% (Table 3). The average age of IgG negative staff was $32.47 \pm 7.24$ years, and positive ones were $35.56 \pm 8.4$ years. Five of 21 staff with mumps negative IgG had already been vaccinated because the measles or rubella IgG test was also negative; The remaining 16 staff were offered two doses of MMR vaccine with one month intervals. However, the vaccine rate was low in this group, only 14 of 21 people agreed to be vaccinated. The reason for not being accepted was the probable of test insecurity; Five out of seven staff who did not get vaccinated had previously stated that they had the disease (Table 2). In our study, although male staff were few (19 in total), six of the seronegative mumps were male.

Chickenpox seropositivity rate was highest (96\%). Four staff, aged $23,34,37,42$, were negative, and only one previously stated that they had chickenpox infection; his chickenpox IgG result was borderline. Four staff were offered two doses of chickenpox vaccine at one-month intervals; three agreed to be vaccinated. Thus, the number of seropositive staff rose to 99 (Table 4).

A total of 24 persons were vaccinated after the examination as MMR and varicella (Table 5); The seropositivity rates in all four groups after our vaccination were over $90 \%$ (Table 4). In our study, approximately one third of the staff did not know the history of measles (30\%) or rubella (41\%); in chickenpox (20\%) and mumps (13\%), this rate was lower (Table 2).

\begin{tabular}{|c|c|c|}
\hline Disease & $\begin{array}{l}\text { Seropositivity before } \\
\text { vaccination } \mathbf{n}(\%)\end{array}$ & $\begin{array}{l}\text { Seropositivity after } \\
\text { vaccination } \mathbf{n}(\%)\end{array}$ \\
\hline Measles & $89(89 \%)$ & $97(97 \%)$ \\
\hline Rubella & $93(93 \%)$ & $98(98 \%)$ \\
\hline Mumps & $79(79 \%)$ & $91(91 \%)$ \\
\hline Varicella & $96(96 \%)$ & 99 (99\%) \\
\hline
\end{tabular}

Table 2. The numbers and rates of MMR and chickenpox infection history or vaccination history before screening; and vaccination rates after screening

\begin{tabular}{|c|c|c|c|c|c|c|c|}
\hline \multirow[t]{2}{*}{ Disease } & \multicolumn{3}{|c|}{ Infection history before screening (n, \%) } & \multicolumn{2}{|c|}{$\begin{array}{l}\text { Vaccination history before } \\
\text { screening }(\mathrm{n}, \%)\end{array}$} & \multicolumn{2}{|c|}{$\begin{array}{l}\text { Vaccination status after } \\
\text { screening }(\mathbf{n}, \%)\end{array}$} \\
\hline & Yes & No & Not know & Yes & No & Yes & No \\
\hline Measles (-) & $1(9 \%)$ & $5(45,5 \%)$ & $5(45,5 \%)$ & $1(9 \%)$ & $10(91 \%)$ & $8(73 \%)$ & $3(27 \%)$ \\
\hline Measles (t) & $40(40 \%)$ & $30(30 \%)$ & $30(30 \%)$ & $10(10 \%)$ & $90(90 \%)$ & $17(17 \%)$ & $83(83 \%)$ \\
\hline Rubella (-) & 0 & $4(57 \%)$ & $3(43 \%)$ & 0 & $7(100 \%)$ & $5(71 \%)$ & $2(29 \%)$ \\
\hline Rubella (t) & $26(26 \%)$ & $33(33 \%)$ & $41(41 \%)$ & $10(10 \%)$ & $90(90 \%)$ & $14(14 \%)$ & $86(86 \%)$ \\
\hline Mumps (-) & $9(43 \%)$ & $7(33 \%)$ & $5(24 \%)$ & $1(5 \%)$ & $20(95 \%)$ & $14(67 \%)$ & $7(33 \%)$ \\
\hline Mumps (t) & $65(65 \%)$ & $22(22 \%)$ & $13(13 \%)$ & $10(10 \%)$ & $90(90 \%)$ & $24(24 \%)$ & $76(76 \%)$ \\
\hline Chickenpox (-) & $2(50 \%)$ & $2(50 \%)$ & 0 & 0 & $4(100 \%)$ & $3(75 \%)$ & $1(25 \%)$ \\
\hline Chickenpox (t) & $65(65 \%)$ & $15(15 \%)$ & $20(20 \%)$ & $2(2 \%)$ & $98(98 \%)$ & $5(5 \%)$ & $95(95 \%)$ \\
\hline Total (-) & & & & $2(6 \%)$ & $32(94 \%)$ & $24(71 \%)$ & $10(29 \%)$ \\
\hline Total (t) & & & & $12(12 \%)$ & $88(88 \%)$ & $34(34 \%)$ & $66(66 \%)$ \\
\hline
\end{tabular}

\begin{tabular}{|lccccc|}
\hline Table 3. Number and rates of positive IgG results by age groups \\
\begin{tabular}{|l} 
Age \\
range
\end{tabular} & $\begin{array}{c}\text { Number of } \\
\text { staff (n) }\end{array}$ & $\begin{array}{c}\text { Measles IgG+ number/ } \\
\text { percentage } \\
\text { (n)/(\%) }\end{array}$ & $\begin{array}{c}\text { Rubella IgG+ number/ } \\
\text { percentage } \\
\text { (n)/(\%) }\end{array}$ & $\begin{array}{c}\text { Mumps IgG+ number/ } \\
\text { percentage } \\
\text { (n)/(\%) }\end{array}$ & $\begin{array}{c}\text { Chickenpox IgG+ } \\
\text { number/percentage } \\
(\mathbf{n}) /(\%)\end{array}$ \\
\hline $20-29$ & 33 & $27(82 \%)$ & $32(97 \%)$ & $23(70 \%)$ & $32(97 \%)$ \\
$30-39$ & 38 & $36(95 \%)$ & $36(95 \%)$ & $33(87 \%)$ & $36(95 \%)$ \\
$40-49$ & 25 & $22(88 \%)$ & $22(88 \%)$ & $19(76 \%)$ & $24(96 \%)$ \\
$50-59$ & 4 & $4(100 \%)$ & $3(75 \%)$ & $4(100 \%)$ & $4(100 \%)$ \\
Total & 100 & $89(89 \%)$ & $93(93 \%)$ & $79(79 \%)$ & $96(96 \%)$ \\
\hline
\end{tabular}

IgG: Immunglobulin G 


\begin{tabular}{|c|c|}
\hline \multicolumn{2}{|l|}{ Feature } \\
\hline \multicolumn{2}{|l|}{ Gender $\mathbf{n}(\%)$} \\
\hline Male & $7(21 \%)$ \\
\hline Female & $27(79 \%)$ \\
\hline The average age & $33.67 \pm 7.35$ years \\
\hline The average of professional year & $9.32 \pm 7.82$ years \\
\hline $\begin{array}{l}\text { Number of staff who accepted vaccination } \\
\mathrm{n}(\%)\end{array}$ & $24(71 \%)$ \\
\hline IgG negativity (accepted vaccination) & Vaccinations made (n) \\
\hline Measles & $\operatorname{MMR}(4)$ \\
\hline Rubella & $\operatorname{MMR}(3)$ \\
\hline Mumps & MMR (10) \\
\hline Varicella & $\mathrm{C}(2)$ \\
\hline Mumps+rubella & $\operatorname{MMR}(1)$ \\
\hline Mumps+measles & $\operatorname{MMR}(2)$ \\
\hline Measles+rubella & MMR (1) \\
\hline Mumps+measles + chickenpox & $\mathrm{MMR}+\mathrm{C}(1)$ \\
\hline Total & 24 \\
\hline
\end{tabular}

\section{DISCUSSION}

Our Ministry of Health stated that, medical faculties, nurses and midwifery faculties, dentistry faculties, students of medical schools, all HCWs, including health institution cleaners, staff working in emergency service, emergency health vehicles, and National Medical Rescue Team staff, should receive MMR, chickenpox, Td, influenza, hepatitis A and B vaccines (6). Vaccination against these diseases prevents possible epidemics in health institutions; it prevents a great economic loss in terms of treatment costs (4). In our country, the adult vaccination rate (below 2\%) is generally very low (7). However, in order to minimize the probability of an outbreak, the immunity rate should be above $95 \%$ (8). In our study, only the rate of seropositivity of chickenpox was found to be above 95\% in all age groups (Table 3).

According to the results of surveillance studies in our country; 8042 of measles cases were detected in the outbreak in 2013, and $1.4 \%$ of them (96 cases) were reported to be HCWs (9). Epidemics can be seen not only in the unvaccinated population, but also in the population with reduced vaccine protection (reduced IgG) (10). In our country, some conditions are required for the healthcare professionals to be considered immune to measles. The first is that the history of measles is documented by a physician. Others are the presence of measles IgG positivity approved by a laboratory, born before 1957 or an official document indicating that two doses of measles were vaccinated (11). Turkey has been started measles vaccine after the 1970; while two doses were made between 1970-1987 and one dose between 1987-1998, they were increased to two doses again after $1998(12,13)$. The fact that the lowest seropositivity rate was in the staff born between 1987-1998 in our study made us think that it may be due to insufficient vaccine dose. More research is needed on this subject. In the study conducted by Aypak et al. (14) as in our results, the lowest seropositivity rate $(79.2 \%)$ was observed in the young group under 25 years of age, and the overall rate was found similar to our study with $90.8 \%$. However, in the study of Özgüler et al. (15) the rate of measles seropositive staff is quite high with $99.1 \%$.

Between 2006 and 2018, the number of confirmed rubella cases in our country was 1236 , but an average of 95 cases per year are observed (9). In our study, the overall seropositivity rate of rubella was $93 \%$ (93 HCWs), and unlike measles, the lowest rate was in the 50-59 age group. It was noteworthy that the higher the age between the groups, the lower the positivity rate (Table 3 ). In some studies conducted in our country, this situation was found to be opposite and a partial increase in seropositivity was observed as the age progressed $(14,16)$.

In our country, mumps vaccine has been included in the routine vaccination program since 2006 as a childhood vaccine (13). In our study, mumps IgG positivity rate was the lowest with $79 \%$. In studies conducted in our country, seropositivity rates vary between $82.5-99.7 \%$ (14,16-19). According to these results, our rate is very low. The mumps IgG result was borderline in nine case, negative in 12; the most borderline was seen in mumps IgG. In addition, six of the nine staff previously declared that they had mumps infection. The history given in rash diseases such as measles and rubella could not be reliable; however, the history of the disease was more reliable because the symptoms of chickenpox and mumps were more specific (20). This made us think that even if it is naturally immune, there may be a decrease in mumps IgG titer over the years. However, more studies are needed on this subject.

In a study reported from a center with employees from different countries, chicken pox IgG positivity rate is quite low with $81.9 \%$. The lowest rates; according to age was seen above 40 years $(74.1 \%)$ and according to countries was seen at India (76.5\%) (21). Studies in our country, it has been reported that the rate of seropositivity is between $98-99.7 \%(14,16-18)$. In our study, we found that the rate of chickenpox seropositivity was close to the general literature rates (96\%).

Vaccines planned according to occupational hazards differ from country to country and even from center to center (22). Therefore, different results of seroprevalence studies are a concomitant. For example, in a study conducted in Italy, chicken pox IgG positivity rate was found as $97.9 \%$; in another study conducted in Italy, $85.7 \%$ was detected $(23,24)$. In a survey study on 
occupational risks to health high school students; $94.5 \%$ of students knew that hepatitis B vaccine should be given to HCWs, while $72.7 \%$ knew that MMR vaccine should be given (25). This study made us think that one of the reasons for the low seropositivity rates may be the lack of information. Therefore, training about vaccines should be given to students and staff frequently.

The other subject; although the rate of not remembering the history of the disease is high in our group, the rate of vaccination is low. However, people who are recommended vaccines after the examination have a high rate of vaccination. Therefore, it is thought that the lack of information rather than distrust, neglect and seropositivity may be the reason for not being vaccinated. In a multicenter study conducted with HCWs in our country, it was reported that only a small group (15.5\%) was vaccinated for MMR. In our study, our pre-screening vaccination rate is similar to $12 \%$; however, this rate increased to $34 \%$ after screening (26). Although the use of live viral vaccines such as MMR mimics the natural infection that provides life-long protection; Studies have shown that immunity is reduced even in fully vaccinated individuals, especially in measles and mumps (27). In our results, the lowest rates belong to measles (89\%) and mumps (79\%).

Our study showed that our healthcare staff were at risk, especially in terms of mumps, and $29 \%(6 / 21)$ of the personnel who were seronegative for mumps were male. In addition, our seropositivity rate for measles was lower compared to the country average. It was noteworthy that most of the HCWs who were seronegative for measles, rubella, mumps and chickenpox did not have the vaccine before the examination, despite all the recommendations, but when the result was negative after the examination, most of them $(71 \%)$ had the vaccine we recommended. Some of the people who did not have the vaccine were pregnant and some were people with chronic diseases. Others were sure that they had an illness, but did not have it because of a lack of confidence due to the negative test. Our high seropositivity rate for chickenpox and rubella were similar to those detected in other studies in Turkey. However, low seropositivity rates against mumps and measles were not consistent with these studies.

\section{CONCLUSION}

In a country with such a high rate of migration as Turkey, it should be noted that especially who work in high-risk places as a hospital must be vaccinated. Even before meeting the patient, vaccination should be recommended on the first day of starting work or in health-related schools, if they do not agree to have it, measles, rubella, mumps and chickenpox IgG tests should be requested. Our study can be an evidence for compliance with the vaccine recommendations of the Ministry of Health. In addition, the vaccination of the HCW is important in terms of not only being an example for the people who are against the vaccine, but also in terms of not interrupting the health service. Some studies suggest that HCWs should be vaccinated without screening because it is not cost-effective (18). Despite this, it has been observed that staff vaccination rates are low in many centers (26). Since our vaccination rate was low, we decided to screen our staff with the decision of the Infection Committee Control, and we saw a significant increase in the rate of vaccination afterwards. For this reason, we think that HCWs should be screened in order to increase vaccination rates and healthcare workers who are seronegative should be encouraged to vaccinate.

\section{ETHICAL DECLARATIONS}

Ethics Committee Approval: The study was carried out with the permission of Non-Invasive Health Research Ethics Committee of Düzce University (permission granted: 07.01.2019, decision no: 244).

Informed Consent: Because the study was designed retrospectively, no written informed consent form was obtained from patients.

Referee Evaluation Process: Externally peer-reviewed.

Conflict of Interest Statement: The authors have no conflicts of interest to declare.

Financial Disclosure: The authors declared that this study has received no financial support.

Author Contributions: All of the authors declare that they have all participated in the design, execution, and analysis of the paper, and that they have approved the final version.

Acknowledgments: I would like to thank Infection Committee Control of Akçakoca State Hospital for their contribution.

\section{REFERENCES}

1. Kaçmaz B, Tuna A, Gül S, et al. Evaluation of side effects of measles-mumps-rubella vaccine administered to health care workers. Anatolian Curr Med J 2019; 1: 23-5.

2. Şengöz M, Pişkin N, Aydemir H, et al. Seroprevalence of Measles, Rubella, Mumps and Varicella in Health Care Workers. Klimik J 2019; 32: 46-51.

3. Centers for Disease Control and Prevention [Internet]. Recommended vaccines for healthcare workers. [cited $2020 \mathrm{Apr}$ 20]. Available from: https://www.cdc.gov/vaccines/adults/recvac/hcw.html).

4. Almuneef MA, Memish ZA, Balkhy HH, Otaibi B, Helmi M. Seroprevalence survey of varicella, measles, rubella, and hepatitis $A$ and $B$ viruses in a multinational healthcare workforce in Saudi Arabia. Infect Control Hosp Epidemiol 2006; 27: 1178-83. 
5. T.C. Ministry of Health Public Health Institution [Internet] Necessary vaccines and application schemes for healthcare professionals. [cited 2020 Apr 20]. Available from: https://hsgm. saglik.gov.tr/tr/saglik-calisanlari-asilama.html).

6. T.C. Ministry of Health Public Health Institution [Internet] Vaccination due to occupational risks. [cited 2020 Apr 22]. Available from: https://asi.saglik.gov.tr/asi-kimlere-yapilir/ liste/32 - mesle $\% \mathrm{C} 4 \% 9 \mathrm{Fe}-\mathrm{ba} \% \mathrm{C} 4 \% 9 \mathrm{Fl} \% \mathrm{C} 4 \% \mathrm{~B} 1$-risklernedeniyle-a\%C5\%9F\%C4\%B1lama.html )

7. National Vaccine Workshop Report. T. C. Ministry of Health Infectious Diseases Association. 27-29 March 2014, Ankara.

8. Köse H, Temoçin F. Measles seroprevalence in Yozgat city hospital employees. Klimik J 2018; 31: 144-7.

9. T.C. Ministry of Health, General Directorate of Public Health, Microbiology Reference Laboratories and Biological Products Department. 2020. Measles and rubella surveillance. [cited 2020 Apr 29]. Available from: https://hsgm.saglik. gov.tr/tr/surveyanslar/liste/k\%C $4 \% \mathrm{~B} 1 \mathrm{zam} \% \mathrm{C} 4 \% \mathrm{~B} 1 \mathrm{k}$ ve - k \% C 4 \% B 1 z a m \% C 4 \% B 1 k \% C $3 \%$ A 7 \% C 4 \% B 1 k surveyans\%C4\%B1.html ).

10. Wicker S, Maltezou HC. Vaccine-preventable diseases in Europe: where do westand? Expert Rev Vaccines 2014; 13: 979-87.

11. Güler Ö. Healthcare worker immunization. In: Mutlu B, editor. Adult Immunization. 1st Edition. Ankara: Turkey Clinics; 2019:51-6.

12. Kurugöl Z. Measles in Turkey: Ongoing problems. Turkey Clinics J Pediatr 2006; 15: 52-8.

13. National Pediatrics Association. [cited 2020 May 13]. Available from: https://www.millipediatri.org.tr/Custom/Upload/files/ asilama.pdf

14. Aypak C, Bayram Y, Eren H, Altunsoy A, Berktas M. Susceptibility to measles, rubella, mumps, and varicella zoster viruses among healthcare workers. J Nippon Med Sch 2012; 79: 453-8.

15. Özgüler M, Saltık-Güngör L, Kaygusuz T, Papila Ç. Seroprevalence of hepatitis A, hepatitis B, measles and rubella in health workers of Elazığ Training and Research Hospital. Klimik J 2016; 29: 10-4.

16. Cilız N, Hörü G, Ecemiş T, Şenol Ş, Akçalı S, Kurutepe $S$. Seroprevalance of measles, rubella, mumps, varicella, diphtheria, tetanus and hepatitis b in healthcare workers. Klimik J 2013; 26: 26-30.

17. Alp E, Cevahir F, Gökahmetoglu S, Demiraslan H, Doganay M. Prevaccination screening of health-care workers for immunity to measles, rubella, mumps, and varicella in a developing country: What do we save? J Infect Public Health 2012; 5: 127-32.

18. Çelikbaş A, Ergönül Ö, Aksaray S, et al. Measles, rubella, mumps, and varicella seroprevalence among healthcare workers in Turkey: is prevaccination screening cost-effective? Am J Infect Control 2006; 34: 583-7.

19. Rüzgar M, Mutlu B, Willke A. Measles and mumps seroprevalence study in healthcare workers. Klimik J 2006; 19: 69-70.

20. Guner E. Determination of awareness and immunization status of diseases and vaccination that can be protected by the health care workers. Specialty thesis in medicine, University of Health Sciences, Bozyaka Training and Research Hospital, Department of Infectious Diseases and Clinical Microbiology, Izmir; 2017.

21. Shady I. Seroprevalence of antibodies against varicella zoster virus and rubella virus among newly recruited expatriate healthcare workers: a crosssectional study. BMJ Open 2018; 8: e019339.

22. Maltezou HC, Wicker S, Borg M, et al. Vaccination policies for health-care workers in acute health-care facilities in Europe. Vaccine 2011; 29: 9557-62.

23. Fedeli U, Zanetti C, Saia B. Susceptibility of health care workers to measles, mumps, rubella and varicella. J Hosp Infect 2002; 51: 133-5.
24. Taddei C, Ceccherini V, Niccolai G, et al. Attitude toward immunization and risk perception of measles, rubella, mumps, varicella and pertussis in health care workers in 6 hospitals of Florance, Italy 2011. Hum Vaccin Immunother 2014; 10: 2612 22.

25. Yıldırım A, Özpulat F. Health profession high school students knowledge and awareness of occupational risks. TTB J Continuous Med Educ 2015; 24: 18-25.

26. Mert D, Tosun S, Esen Yildız I, Alay H, Mistanoğlu Özatay D, Adult Vaccine Working Group. Healthcare Workers' Exposures for Mumps, Measles, Rubella and Varicella Zoster Virus Infections: A Multicenter Survey Study. J Microbiol Infect Dis 2019; 9: 144-9.

27. Davidkin I, Jokinen S, Broman M, Leinikki P, Peltola H. Persistence of measles, mumps, and rubella antibodies in an MMR-vaccinated cohort: a 20-year follow-up. J Infect Dis 2008; 197: 950-6. 